\title{
Obituary Dr. Vicente Cuccia
}

\author{
Marcelo Galarza
}

Received: 26 August 2010 / Accepted: 26 August 2010 / Published online: 11 September 2010

(C) Springer-Verlag 2010

\section{Dear Editor,}

I read with great interest the latest article published by Vicente Cuccia entitled Suprasellar/pineal bifocal germ cell tumors published in Child's Nervous System 2010 of August, volume number 26, pp 1043-9, yet, I found that the author died a few months ago. My congratulations came late.

I met Dr. Cuccia at the National Pediatric Hospital J. P. Garrahan of Buenos Aires during my residency years. He was a profound connoisseur of pediatric neurosurgery, one who was always willing to teach, to show, and to point some of his enormous experience acquired over many years at one of the most impressive pediatric hospitals in the world. Trained in Buenos Aires and later in London, he inspired all of us residents at that time; he exhibited true devotion on the uniqueness of the pediatric neurosurgical field as well as displayed true attachment on the specificity of surgical skills and nuances in the pediatric scenario. As a part of my training, we shared countless hours of fishing.

Maybe Suprasellar/pineal bifocal germ cell tumors is his latest paper, but it truly captured the spirit of Dr.
Cuccia. He showed us all a small group of GCT located simultaneously in the suprasellar and pineal regions without seeding either between both tumors or to other places. He named this group as suprasellar/pineal bifocal germ cell tumors (SPBTs) and pointed that the presence of two tumors does not indicate dissemination as well as the finding that SPBTs were non-disseminated but focal tumors, and also that spinal radiotherapy was not necessary. All are important remarks yet Dr. Cuccia showed reticence about excessive scientific communication. Also, he was not interested to be in the limelight in the pediatric neurosurgical community in spite of his perfect English communication skill and given his former years in the UK even though I insist that he had an exceptional experience in the field.

I am sure that the people from Argentina and South America have lost a great surgeon who helped innumerable children over the years. So long my friend and congratulations for this great article. This is not a typical obituary.

M. Galarza $(\bowtie)$

Regional Service of Neurosurgery,

Hospital Universitario Virgen de la Arrixaca,

E-30120, El Palmar Murcia, Spain

e-mail: Marcelo.galarza@carm.es 